\title{
Article \\ In Silico Inference of Synthetic Cytotoxic Interactions from Paclitaxel Responses
}

\author{
Jeong Hoon Lee ${ }^{1}$ (D) Kye Hwa Lee ${ }^{2, *}$ and Ju Han Kim ${ }^{1, *}$ \\ 1 Seoul National University Biomedical Informatics (SNUBI), Division of Biomedical Informatics, \\ Seoul National University College of Medicine, Seoul 110799, Korea; sosal@snu.ac.kr \\ 2 Asan Medical Center, University of Ulsan College of Medicine, Seoul 05505, Korea \\ * Correspondence: geffa@amc.seoul.kr (K.H.L.); juhan@snu.ac.kr (J.H.K.); Tel.: +82-2-3010-5991 (K.H.L.); \\ +82-2-740-8320 (J.H.K.); Fax: +82-2-3010-2531 (K.H.L.); +82-2-3673-2167 (J.H.K.)
}

check for

updates

Citation: Lee, J.H.; Lee, K.H.; Kim, J.H. In Silico Inference of Synthetic Cytotoxic Interactions from Paclitaxel Responses. Int. J. Mol. Sci. 2021, 22, 1097. https://doi.org/10.3390/ ijms22031097

Academic Editor: Ramón Cacabelos Received: 9 December 2020

Accepted: 19 January 2021

Published: 22 January 2021

Publisher's Note: MDPI stays neutral with regard to jurisdictional claims in published maps and institutional affiliations.

Copyright: (c) 2021 by the authors. Licensee MDPI, Basel, Switzerland. This article is an open access article distributed under the terms and conditions of the Creative Commons Attribution (CC BY) license (https:// creativecommons.org/licenses/by/ $4.0 /)$.

\begin{abstract}
To exploit negatively interacting pairs of cancer somatic mutations in chemotherapy responses or synthetic cytotoxicity (SC), we systematically determined mutational pairs that had significantly lower paclitaxel half maximal inhibitory concentration $\left(\mathrm{IC}_{50}\right)$ values. We evaluated 407 cell lines with somatic mutation profiles and estimated their copy number and drug-inhibitory concentrations in Genomics of Drug Sensitivity in Cancer (GDSC) database. The SC effect of 142 mutated gene pairs on response to paclitaxel was successfully cross-validated using human cancer datasets for urogenital cancers available in The Cancer Genome Atlas (TCGA) database. We further analyzed the cumulative effect of increasing SC pair numbers on the TP53 tumor suppressor gene. Patients with TCGA bladder and urogenital cancer exhibited improved cancer survival rates as the number of disrupted SC partners (i.e., SYNE2, SON, and/or PRY) of TP53 increased. The prognostic effect of SC burden on response to paclitaxel treatment could be differentiated from response to other cytotoxic drugs. Thus, the concept of pairwise SC may aid the identification of novel therapeutic and prognostic targets.
\end{abstract}

Keywords: synthetic cytotoxicity; conditional synthetic lethality; paclitaxel; chemotherapy response; urogenital cancer

\section{Introduction}

Despite the presence of targeted therapies and increasing number of genomic biomarkers, cytotoxic chemotherapy, which damages cells and causes rapid cell death, remains the gold standard for most treatment of most cancers [1-4]. Paclitaxel, one of the most commonly used cytotoxic agents, is a mitotic inhibitor used for chemotherapeutic treatment of various cancers [5]. In recent years, several attempts have been made to identify biomarkers that affect paclitaxel responses in cancer cell lines and cancer patients using genetic profiles such as mRNA expression and exome sequencing [6-8]. Unlike target-specific drugs, cytotoxic drugs result in highly variable patient outcomes, making the prediction of responsiveness challenging using genomic profiles, which can otherwise provide some insights into nonspecific antiproliferative or cytotoxic effects [9].

Currently, several anticancer therapies exploit somatic mutations and oncogene overexpression, independent of tumor dependence on specific oncogenic pathways for survival [10-13]. Although oncogene-targeting inhibitors are effective for some cancer patients, not all cancer cells express these targets. As another treatment option, synthetic lethal approach targets one of the negative genetic interactions in the second site, which functionally disrupts both the genes simultaneously, leading to cancer cell death [10,11]. Negative genetic interaction-based approaches can be expanded for using chemotherapeutic agents based on response data such as the half-maximal inhibitory concentration $\left(\mathrm{IC}_{50}\right)$ or the halfmaximal effective concentration $\left(\mathrm{EC}_{50}\right)$. Synthetic cytotoxicity $(\mathrm{SC})$, a conditional synthetic lethal interaction, increases the cytotoxicity of chemotherapeutic agents when functions of 
specific gene pairs are disrupted simultaneously. SC does not occur when only one gene is disrupted. Interestingly, $\mathrm{Li}$ Xuesong et al. (2014) performed a series of yeast experiments, including synthetic genetic and plate assays, to show that digenic disruption due to the TEL1/ATM mutation leads to SC with camptothecin, a topoisomerase I inhibitor [14].

Many computational approaches that exploit the theory of synthetic lethality have been used to identify new therapeutic targets $[12,15,16]$. For example, Jang et al. used deep learning modeling to predict lethality based on an RNA regulatory network from in vitro screening data [17]. Moreover, computationally inferred candidate synthetic lethal pairs from various algorithms have already been organized, and a database has been constructed [18]. However, to the best of our knowledge, none of the computational approaches have taken advantage of the theory of SC that enhances chemotherapeutic drug responses. The highly variable nature of chemotherapy responses prevents prediction of personalized responses. Therefore, we hypothesize that in silico methods can identify SC pairs to aid the development of novel anticancer therapies.

Here, we focused on the chemotherapeutic agent paclitaxel, and using Genomics of Drug Sensitivity in Cancer (GDSC) cell line data, we identified SC mutational pairs that increase the anticancer effect of paclitaxel via conditional synthetic lethality. Moreover, we validated these findings using The Cancer Genome Atlas (TCGA) genome profiles and clinical data. Among many identified candidate SC pairs, we tested the SC partner genes of TP53, an important tumor suppressor gene with a high frequency of somatic mutation, to validate SC and the prognostic effects in patients with bladder urothelial and uterine corpus endometrial carcinoma included in TCGA.

\section{Results}

\subsection{SC Network of Paclitaxel}

We analyzed 407 GDSC cancer cell lines to identify somatic mutation profiles, copy number estimations, and $\mathrm{IC}_{50}$ values for paclitaxel [19]. This led to the identification of 142 SC pairs of mutated genes (consisting of 95 genes) by integrating the mutational and drug sensitivity profiles (Figure 1). A paclitaxel SC network was created by defining genes as nodes and positive SC interactions as edges. The SC network consisted of three main subnetworks and two singleton SC pairs with an average degree of 2.989 (Figure 2). The size of a node represents a network degree. Of the 95 genes, AHNAK2 exhibited the highest degree of 13, followed by PLEC and ANKRD30A, both with a degree of 12 .

\subsection{SC Gene Pairs Were Enriched for Cell Death and Chemical Responses}

To investigate the characteristics of these SC interactions, functional enrichment analysis was performed for the SC network genes with Gene Annotation Tool to Help Explain Relationships (GATHER) network inference. Figure 3 illustrates the result of functional enrichment analysis using Gene Ontology (GO) and the GATHER with network inference. Notably, the three clusters were significant based on enrichment analysis. The first cluster was enriched in terms related to cell proliferation and developmental processes. The second cluster was enriched in GO terms for chemical responses. The third cluster was enriched in the GO terms associated with cell death. 


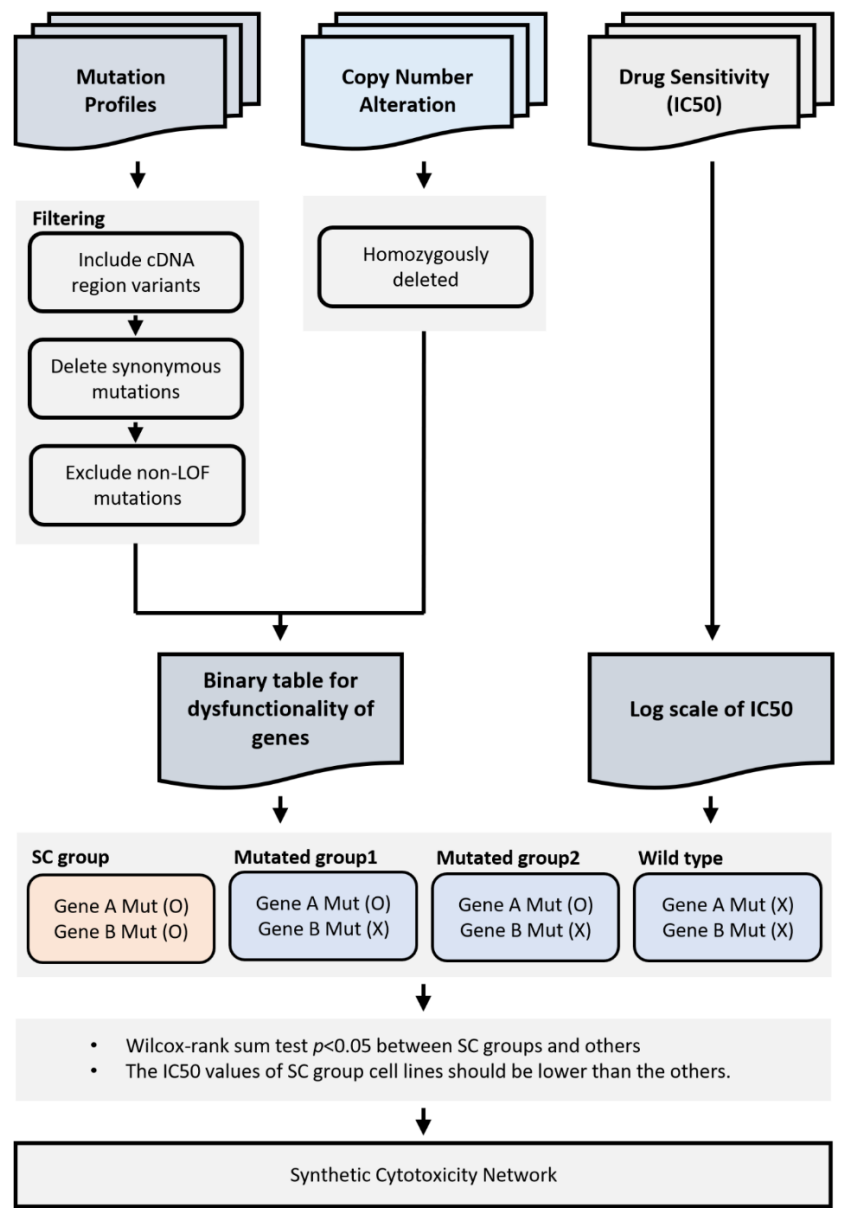

Figure 1. Workflow scheme for inferring synthetic cytotoxicity. All cancer cell lines were divided into four groups and defined based on the disruption of two genes. A synthetic cytotoxic pair is defined when both disrupted genes have significantly lower $\mathrm{IC}_{50}$ than those in the other three groups.

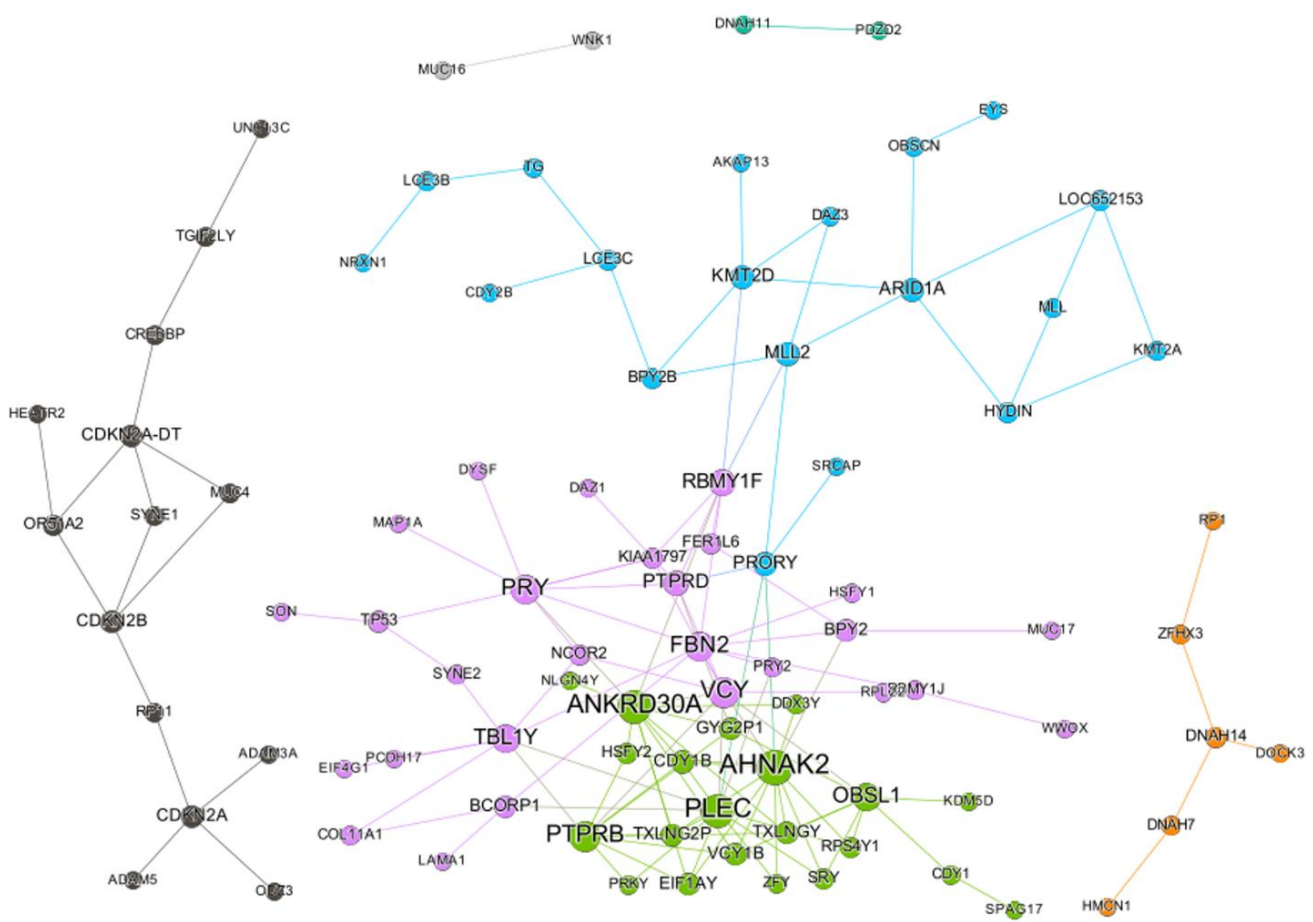

Figure 2. Inferred synthetic cytotoxic interaction network of paclitaxel. 


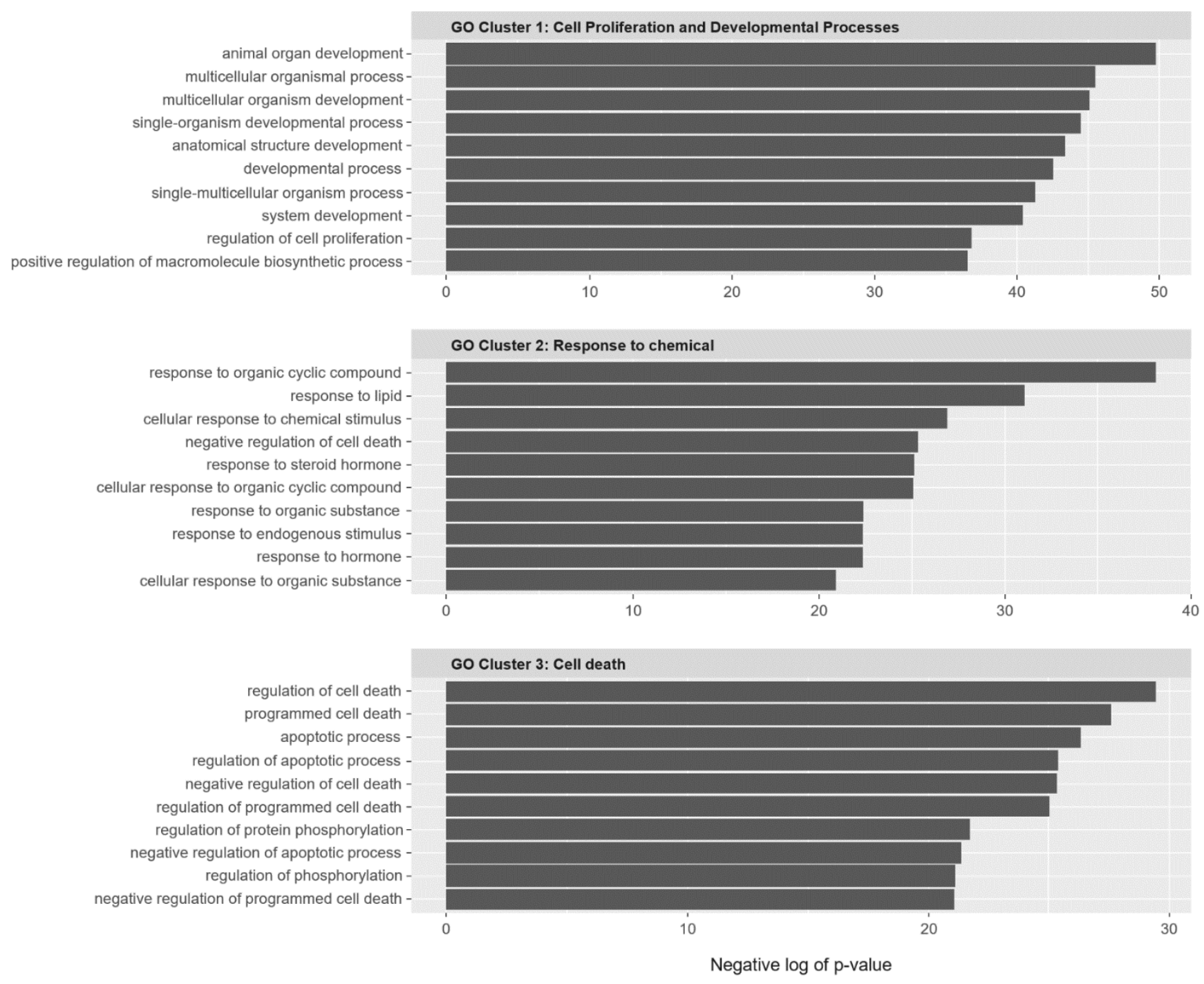

Figure 3. Functional enrichment analysis of the Kyoto Encyclopedia of Genes and Genomes (KEGG) pathway and gene ontology for 95 genes involved in synthetic cytotoxic interactions. These genes were significantly enriched in terms related to cell death and response to chemical and biological processes.

\subsection{SC Burden}

An SC interaction was defined as a better response to paclitaxel (i.e., lower $\mathrm{IC}_{50}$ value) when both genes in an interacting pair were disrupted (details in method section). By counting the number of SC pairs, we classified the 407 samples into four SC burden groups (i.e., Group 1 with no SC pair $(N=112)$, Group 2 with one to two SC pairs $(N=103)$, Group 3 with three to nine SC pairs $(N=86)$, and Group 4 with more than nine SC pairs $(N=106$; Figure 4). As expected, the higher the SC burden, the lower the median log $\mathrm{IC}_{50}$ value for paclitaxel (Group $1=-1.953$, Group $2=-3.061$, Group $3=-3.808$, and Group $4=-4.313)$. We determined statistical significance using the Kruskal-Wallis test $(p<0.001)$. In the four SC burden groups, the frequency rankings of SC pairs counted in patients are listed in Supplementary Table S1. 


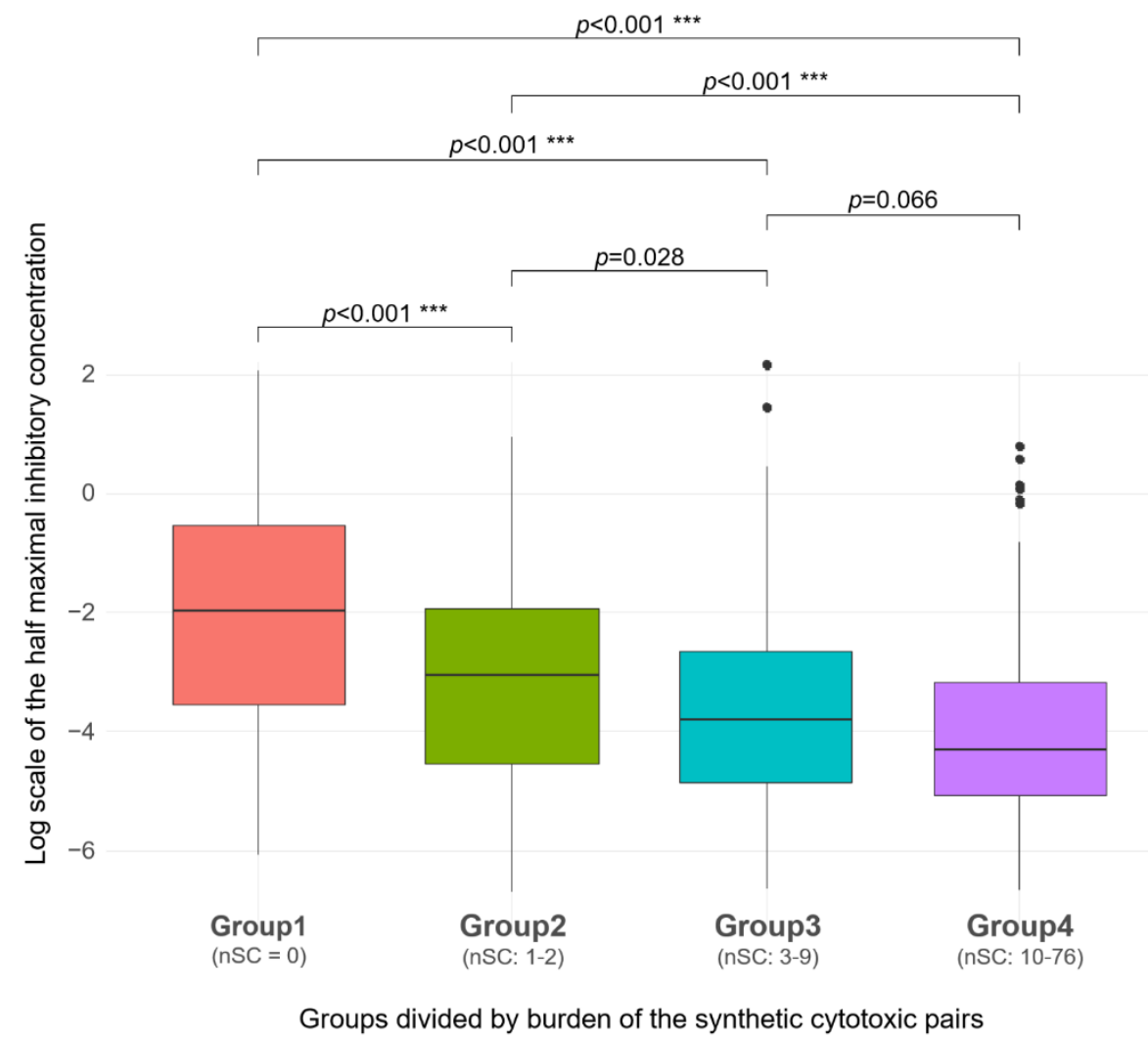

Figure 4. In the four groups divided according to the number of synthetic cytotoxic pairs, groups with more pairs had lower $\mathrm{IC}_{50}$ values. There were 112, 103, 86, and 106 samples in Group 1 to Group 4, respectively.

\subsection{TP53 SC Pairs}

TP53 is a very important tumor suppressor gene with high mutational frequencies in many cancers. TP53 forms SC pairs with three genes, spectrin repeat-containing nuclear envelope protein 2 (SYNE2), negative regulatory element-binding protein $(S O N)$, and PRY (Figure 2). SYNE2 helps maintain the structural integrity of the nucleus [20]. When both TP53 and SYNE2 were disrupted, the response to paclitaxel was significantly better compared with that of the other three cases $(p<0.05$, Wilcoxon test; Figure 5a). The reactome pathway database showed that related pathways for SYNE2 included the cell cycle, mitosis, and meiosis. Additionally, SON promotes splicing of several cell cycle and DNA-repair transcripts containing weak splice sites [21] (Figure 5b). GO analysis revealed that $S O N$ may be involved in the cell cycle, mitotic cytokinesis, microtubule cytoskeleton organization, mRNA processing, and RNA splicing. PRY forms a cytotoxic pair with TP53, however, no biological process terms or pathways are known. However, this gene was excluded from subsequent analysis because $P R Y$ gene disruption was not observed in TCGA patients and was located on the $Y$ chromosome (Figure 5c). Additionally, compared to the 142 SC gene pairs, the PRY-TP53 pair had the least statistical significance.

\subsection{Survival Analysis of Prognostic Subgroups of TP53 SC Network}

Improved response to a chemotherapeutic agent is believed to aid the therapeutic effect in patients. Thus, to validate the effect of SC in the TP53 network, we considered the urogenital system in the TCGA database, including bladder urothelial $(N=406)$ and uterine corpus endometrial $(N=545)$ carcinomas, which are commonly treated with paclitaxel chemotherapy [22]. Clinical characteristics in both cancer patient groups are listed in Table 1. We hypothesized that SC pairs and their increased burden would improve patient prognoses. We constructed a gene disruption matrix using somatic mutation and copy number estimation data available from TCGA. To confirm whether the accumulation of SC 
pairs in TP53 subnetworks was related to patient prognosis, we divided the patients into two groups according to the presence or absence of TP53 disruption. We only analyzed the SC interactions of SYNE2 and SON with TP53, as no PRY mutations were identified in the TCGA database.

a

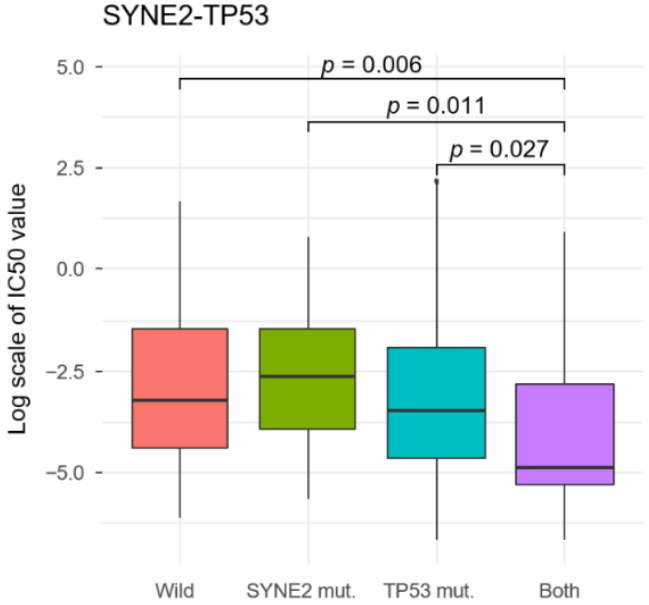

b SON-TP53

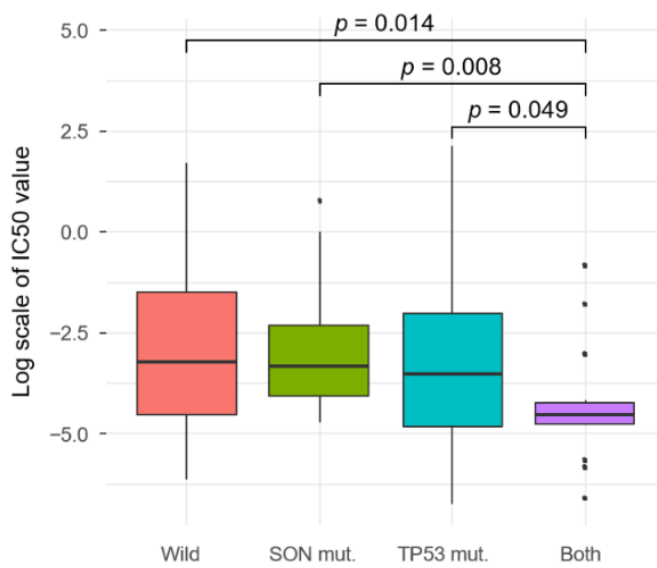

C

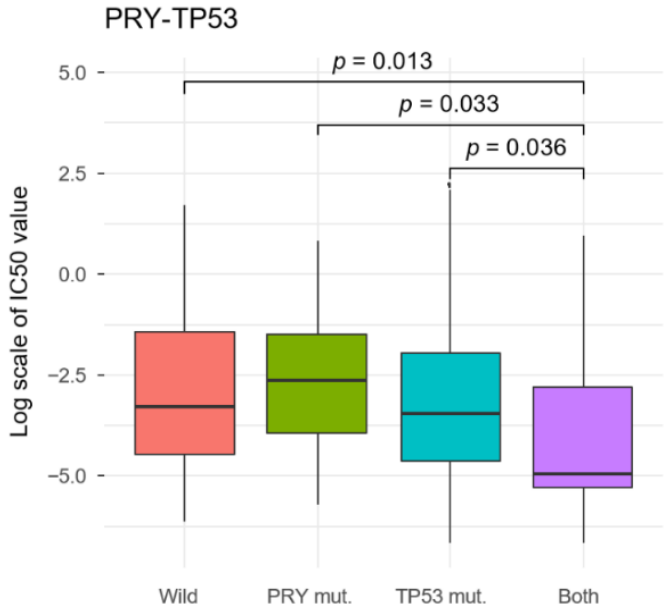

Figure 5. (a-c) Three genes that exert a synergistic effect on TP53 responses to paclitaxel. When the SYNE2, SON, and PRY genes digenically disrupt TP53, the $\mathrm{IC}_{50}$ value of paclitaxel decreases significantly. 
Table 1. Patient characteristics of TCGA validation dataset, bladder urothelial carcinoma and uterine corpus endometrial carcinoma.

\begin{tabular}{ccccc}
\hline \multirow{2}{*}{ Clinical Variables } & \multicolumn{2}{c}{ Bladder Cancer } & \multicolumn{2}{c}{ Uterine Cancer } \\
\cline { 2 - 5 } & TP53 (+) & TP53 (-) & TP53 (+) & TP53 (-) \\
\hline N & 212 & 194 & 199 & 272 \\
\hline Age & $63.73(9.87)$ & $63.01(11.87)$ & $61.98(9.88)$ & $58.31(11.24)$ \\
\hline Survival & & & & \\
Alive & 151 & 145 & 178 & 252 \\
Dead & 61 & 49 & 21 & 45 \\
Gender & & & & \\
Male & 153 & 149 & 0 & 272 \\
Female & 59 & 47 & 199 & 189 \\
Stage & & & & 25 \\
I & 0 & 2 & 98 & 50 \\
II & 63 & 67 & 63 & 8 \\
III & 74 & 64 & 18 & \\
IV & 75 & 59 & & \\
\hline
\end{tabular}

The survival effect (overall survival) was analyzed according to the presence or absence of individual co-mutations to examine gene-induced synergistic effects in combination with TP53 on individual patient prognosis (Figure 6). Patients with bladder urothelial carcinoma were divided into four groups according to the mutations in SYNE2 and TP53. There were 48 patients with mutations in SYNE2 and TP53, 88 patients with mutations in SYNE2, 150 patients with mutations in TP53, and 184 patients with wild-type versions of both genes (Figure 6a). Cox regression with Firth's penalized likelihood method was used for patients with mutations in SYNE2 and TP53, as this was the reference group. Compared with the group with mutations in SYNE2 and TP53, the hazard ratio and $p$-value of wildtype, TP53 mutant, and SYNE2 mutant groups were 2.40 and 0.047, 2.67 and 0.021, and 2.68 and 0.092 , respectively. In the TP53 and SON pair, there were no significant differences between each group, however, the hazard ratio of each group was greater than 1 . The same method was applied to patients with uterine corpus endometrial carcinoma. When the TP53 and SYNE2 mutant groups were referenced, the TP53 group had a $p$ value of 0.094 and a hazard ratio of 2.70 . The SYNE2 and wild-type groups were not significantly different, however, the hazard ratio was greater than 1 . With the SON and TP53 mutant group as the reference, the hazard ratios of the wild-type group were $4.51(p=0.184)$ and $8.43(p=0.033)$, respectively, for the TP53 mutant group, and $9.54(p=0.041)$ for the SYNE2 mutant group.

Figure 7 illustrates the Kaplan-Meier curves for the patients with bladder urothelial (Figure $7 \mathrm{a}, \mathrm{b}$ ) and uterine corpus endometrial (Figure 7c,d) carcinoma, according to the cumulative disruption of SYNE2 and SON with (Figure 7a,c) and without (Figure 7b,d) TP53 mutation. Red lines represent wild-type SYNE2 and SON, green lines indicate a mutation in one of the genes, and blue lines indicate disruption of both genes. While the TP53 mutations (Figure 7a,c) were noted in both cancer types, accumulation of SYNE2 and SON SC pairs showed better prognosis according to the results of Cox regression with Firth's penalized likelihood method $(p<0.05)$. However, patients without the TP53 mutation (Figure $7 \mathrm{~b}, \mathrm{~d}$ ) did not show any difference in prognosis due to cumulative disruption of $S Y N E 2$ and SON $(p>0.05)$. There were no differences in cumulative disruption of SYNE2 and SON in the TP53 nondisrupted group. The number of patients analyzed over time are listed in the risk table under the Kaplan-Meier graph. 

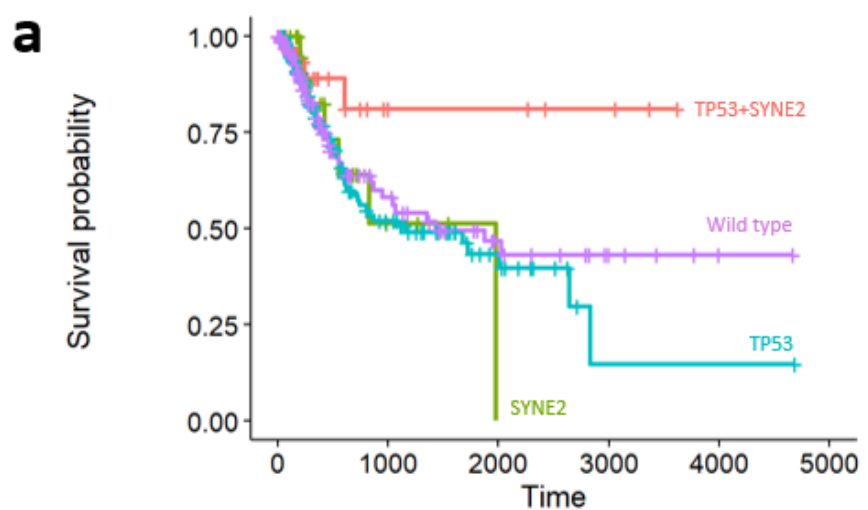

\section{Number at risk}

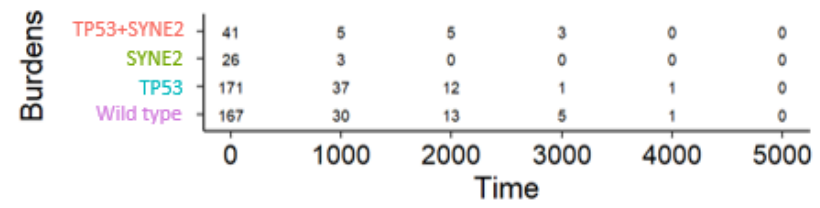

C

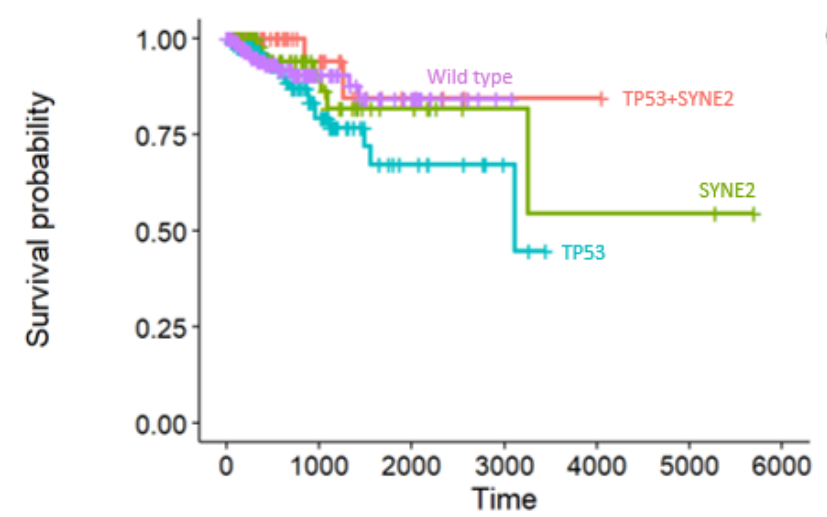

Number at risk

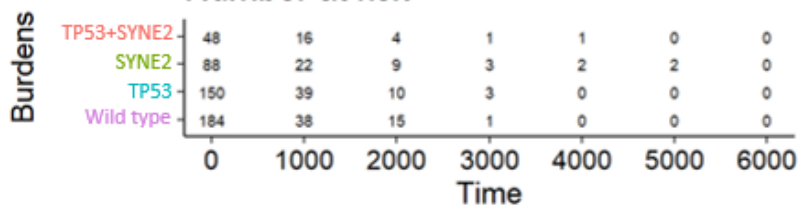

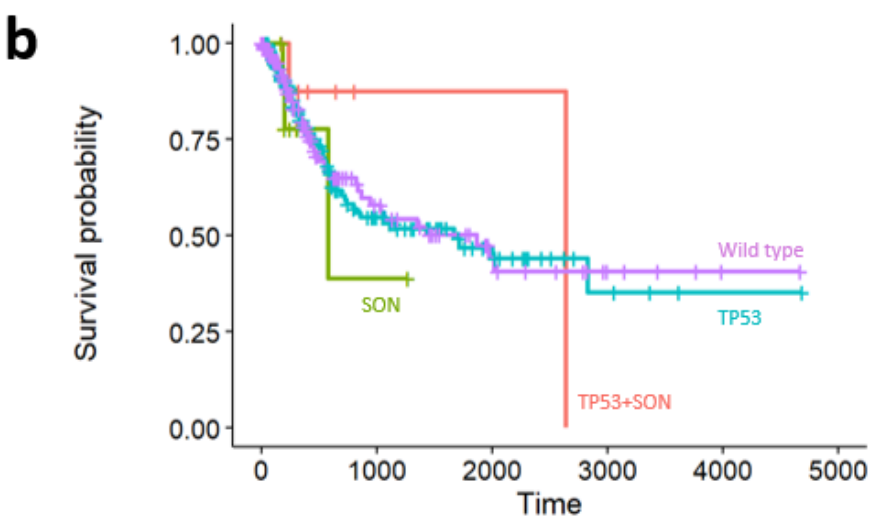

Number at risk
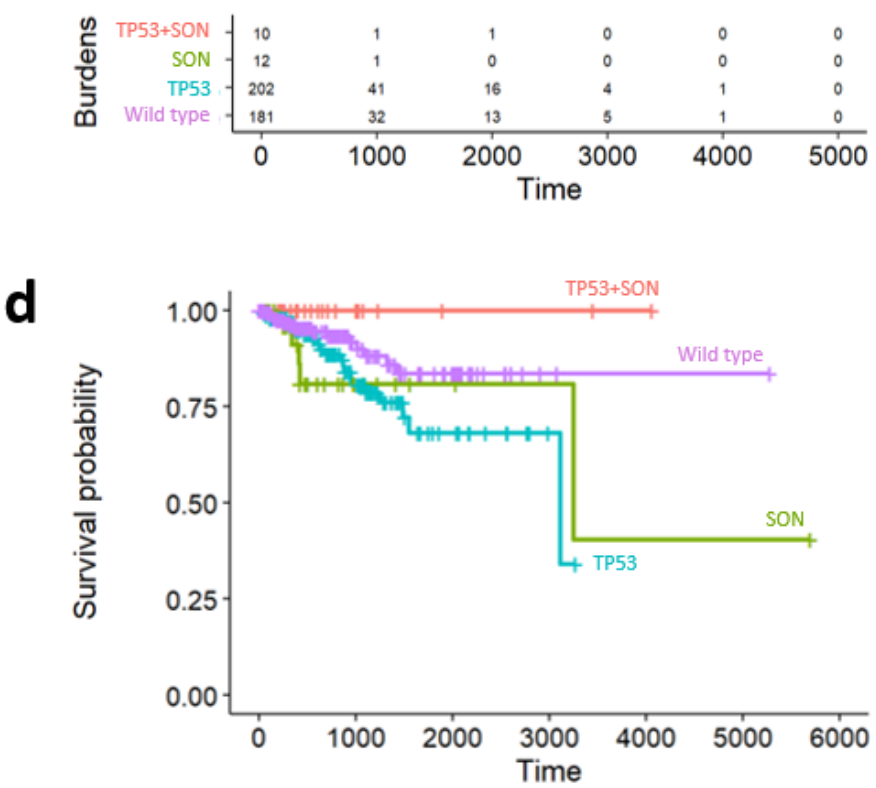

\section{Number at risk}

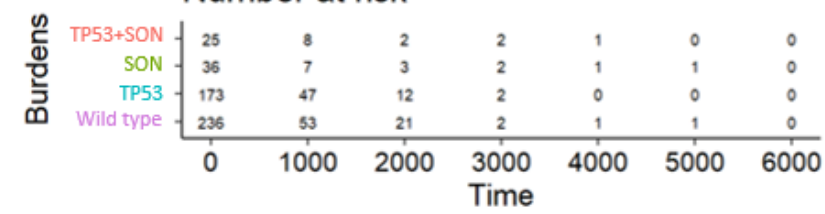

Figure 6. Survival curves according to the events of pair genes constituting synthetic cytotoxicity. (a) Patients with disruption in TP53 and SYNE2 mutations in bladder cancer. (b) Disruption in TP53 and SON mutations in bladder cancer. (c) Patients with disruption in TP53 and SYNE2 mutations in uterine cancer. (d) Disruption in TP53 and SON mutations in uterine cancer.

To confirm the statistical significance of the SC burden with the pathologic stage, multivariate Cox proportional hazard analysis was performed (Supplementary Table S2). Patients without TP53 mutations did not show statistically significant results for survival analysis, regardless of stage significance. Only TP53 mutant patients with an SC burden consistent with the univariate analysis showed significant results for survival analysis. In TP53 mutant bladder cancer, the $p$ value of the SC burden was 0.031 and the hazard ratio was 0.397 , while in TP53 mutant uterine cancer, the $p$ value of the SC burden was 0.035 and the hazard ratio was 0.237 . 
a
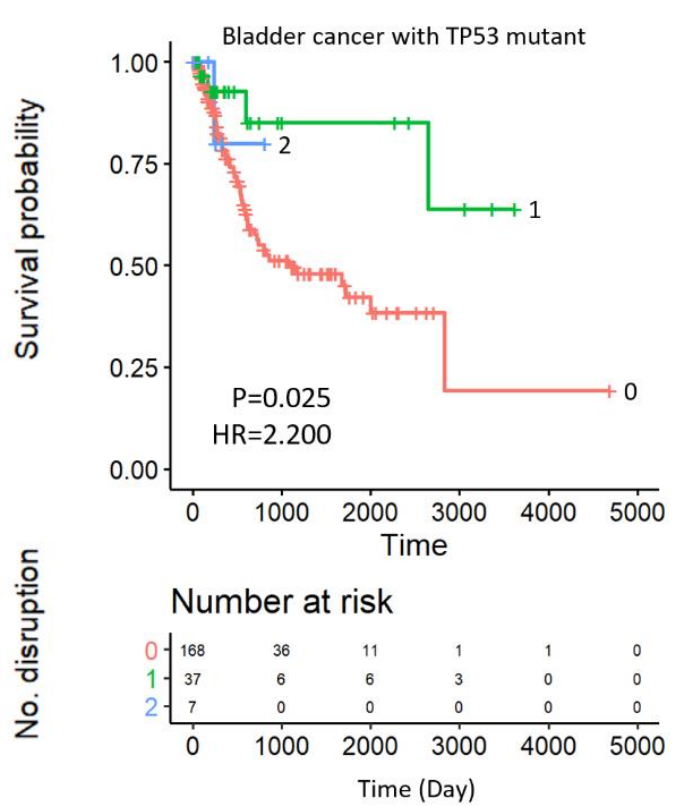

C
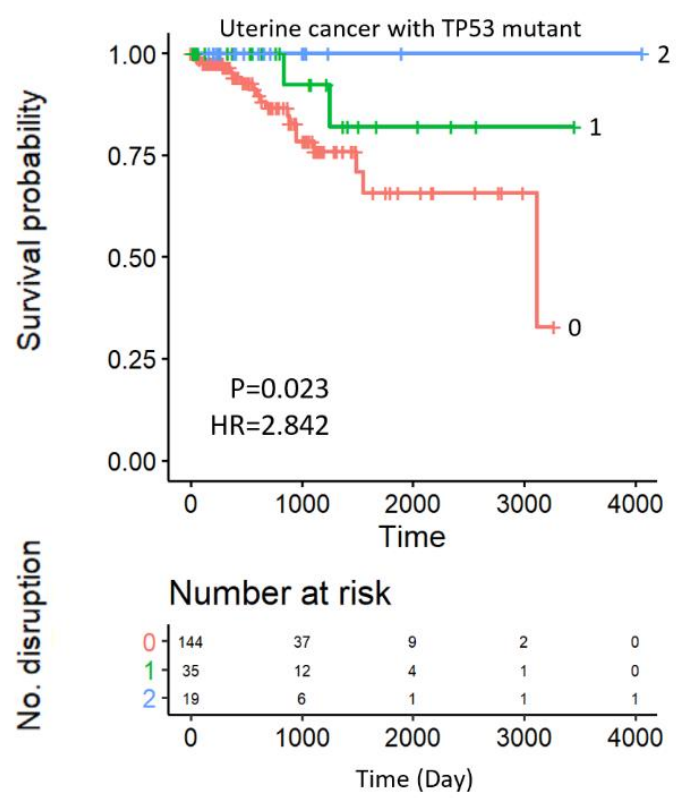

b
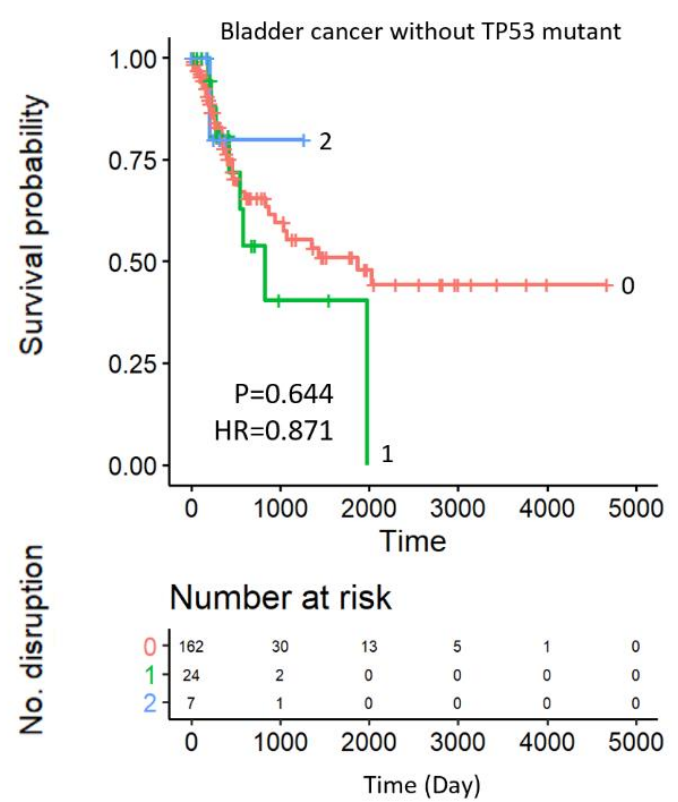

d

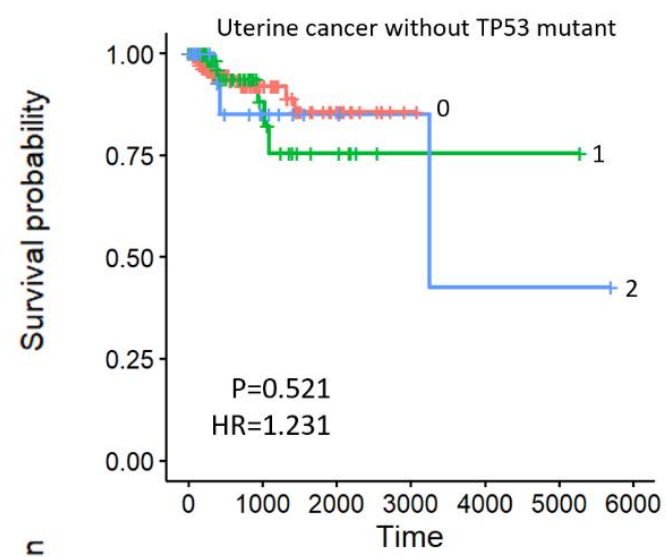

을

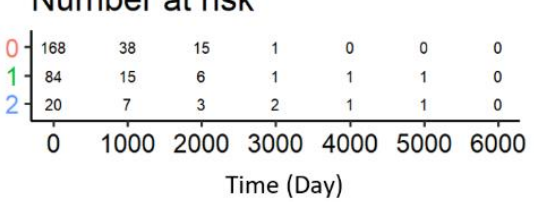

Figure 7. Kaplan-Meier graph for cumulative disruption of SYNE2 and SON, without the TP53 mutation. Red lines denote wild-type SYNE2 and SON, green lines represent mutation in one of the genes, and blue lines represent the disruption of both genes. (a) Patients with bladder cancer with a TP53 mutation. (b) Patients with bladder cancer without a TP53 mutation. (c) Patients with uterine cancer with a TP53 mutation. (d) Patients with uterine cancer without a TP53 mutation.

\subsection{Robustness of Synthetic Cytotoxic Pairs in Chemotherapy Agents}

To assess the robustness of the synthetic cytotoxic pairs to paclitaxel, we tested whether the responses to other drugs were significantly different according to the pair burden. A total of 142 SC pairs were divided into four groups according to the burden, and the distribution of cytotoxic agent response was confirmed. Differences in the $\mathrm{IC}_{50}$ values according to the burden were visualized as boxplots for eight drugs: bleomycin, docetaxel, doxorubicin, epothilone B, etoposide, gemcitabine, pyrimethamine, and vinorelbine (Figure 8). Differences in $\mathrm{IC}_{50}$ values are indicated by the $p$ value for the Wilcoxon test above the boxplot. Our results suggest that the paclitaxel SC pairs can help distinguish the response of other cytotoxic agents. 


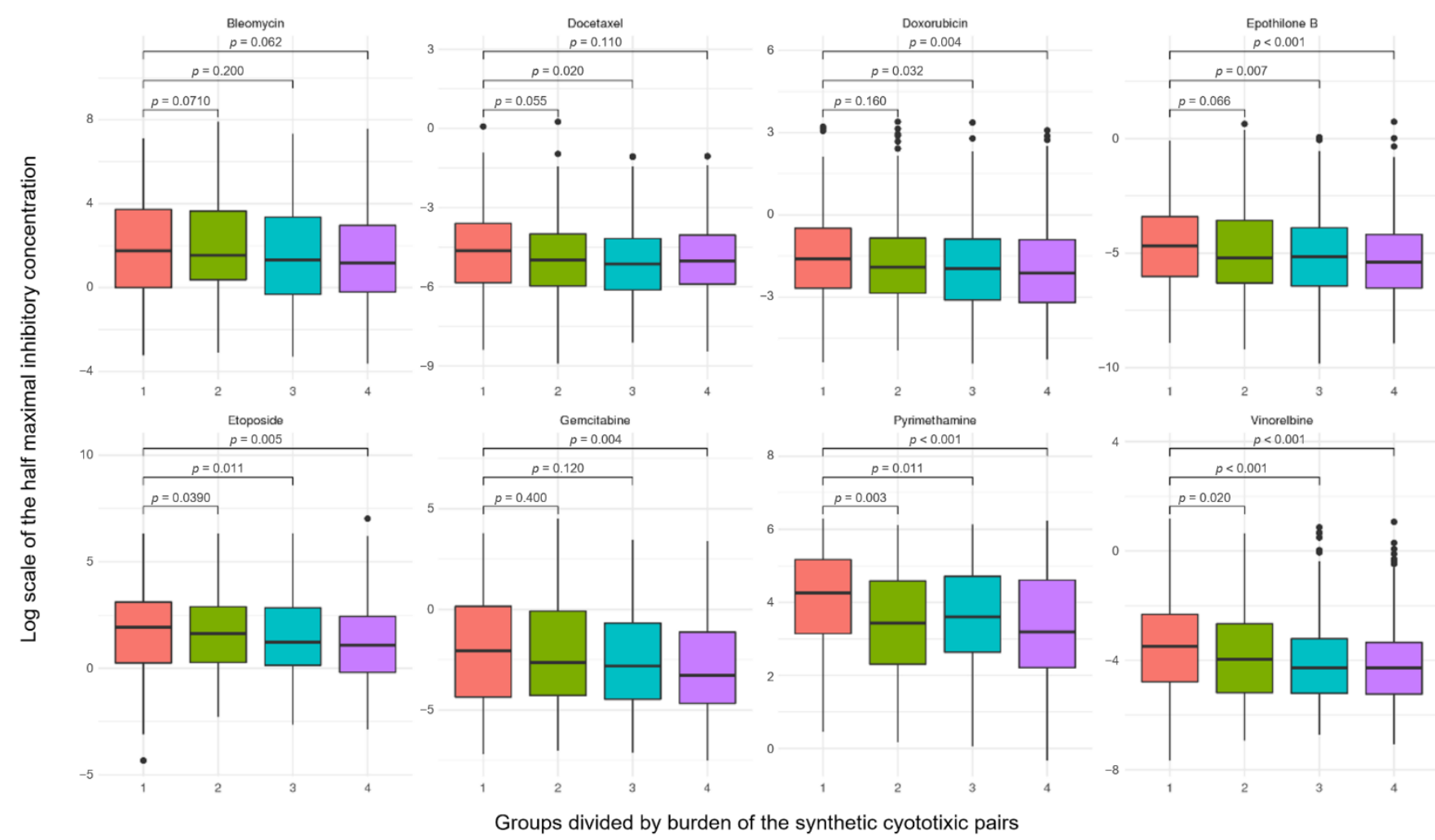

Figure 8. The four groups were divided according to the number of synthetic cytotoxic pairs. The burden of the synthetic cytotoxic pair can significantly differentiate the response to paclitaxel from that to other cytotoxic drugs.

\section{Discussion}

Here, we propose a method for the identification of SC pairs that increase the sensitivity to chemotherapeutic agents, when functions of two genes are disrupted simultaneously. Unlike target-specific drugs, cytotoxic drugs result in highly heterogeneous responses making it difficult to predict patients' responsiveness [1]. Machine learning has been used to predict drug responses based on genetic profiles [23-26]. However, most drugs with good prediction performance are target-specific, while most drugs with poor prediction performance are cytotoxic [9]. Additionally, the identification of biomarkers for predicting responses to cytotoxic agents that cause mutations or copy number changes in the GDSC database has been challenging [27]. As part of our investigation of negative genetic interactions, we proposed a methodology for inferring SC from a genetic profile to deduce gene pairs that can distinguish responses to a specific cytotoxic agent. The synthetic cytotoxic pair we identified in this study showed a prognostic value in the real patient TCGA database. Moreover, we showed that SC against paclitaxel can robustly differentiate responses to other cytotoxic agents.

Cytotoxic agents remain widely used despite the existence of various cancer therapeutic strategies such as targeted therapies and immunotherapy [23]. Cytotoxic agents are inevitably prescribed if targeted therapy is unavailable or if a patient has advanced-stage cancer [1]. Additionally, due to unpredictable therapeutic effects, most cytotoxic agents are often used in combination therapies [28,29]. In selecting a combinatory cytotoxic agent, our method can be utilized as an alternative method of personalized medicine based on an individual's genetic profile. Selection of an anticancer treatment strategy according to an individual gene mutation and dose adjustment can improve patient prognoses and minimize side effects.

Several studies have used machine learning to predict the response to cancer drugs [29-33]. This advanced predictive model successfully predicts drug responses based on genomic data. Meanwhile, our simple methodology approach based on an existing concept of SC is 
also advantageous. Due to the selection of a large number of features (genes) compared to a small data sample and the difference between the cell line and the primary tumor, the machine learning for a complex predictive model (such as deep learning and XGBoost) may be prone to overfitting. However, our approach has been successful with other chemotherapy agents and been verified using patient data from TCGA.

Our SC inference method was designed to predict response to cytotoxic agents. Most cytotoxic agents target complex and heterogeneous processes such as cell cycle and mitosis [34,35]. Paclitaxel is a mitotic inhibitor that rapidly kills dividing cancer cells [5]. Notably, the synthetic cytotoxic genes identified in this study were associated with cell death and responses to chemicals, despite neither being markers for drug responses. Moreover, both SYNE2 and SON, which form important SC interactions with TP53, are involved in the cell cycle [20,21]. Although a single defect in a gene involved in the cell cycle cannot be used to predict drug response, SC, which increases the dimension of the genetic profile, can be used to predict responses to cytotoxic agents reflecting the composition of the complex cell cycle. Studies showing that the tumor mutational burden does not predict cytotoxic chemotherapy responses further support this observation [36,37]. This pair-wise approach can help to identify novel biomarkers and improve the prediction based on a single biomarker, more so, since tumors are heterogeneous and have polyclonal drug-resistant properties [38].

The GDSC database provides a mutational profile for 1001 cell lines and $\mathrm{IC}_{50}$ values for 265 drugs. TCGA is also a large database that provides multiomics data along with the clinical information of real patients. We have shown that although the two databases are built for different purposes, the information available on them can be linked in a complementary manner [39]. We identified a novel biomarker using the concept of SC and the information available on the GDSC database and verified the effect on patient prognosis using the TCGA database.

The TP53 mutation is an important biomarker for tumor recurrence, progression, and prognosis in urogenital cancer $[40,41]$. Although the TP53 is an important predictive biomarker, developing an exploitative therapeutic strategy has been difficult. However, SC exploits the highly mutated TP53 in an unconventional way that allows for the development of novel therapeutic strategies by exploiting other genes. For response to paclitaxel, both SON and SYNE2 genes were found to increase the drug cytotoxicity when disrupted with the TP53 gene. Likewise, identification of a novel negative genetic interaction based on frequently mutated genes (e.g., KRAS) may aid the development of new cancer therapeutic strategies.

However, it is important to note that differences in the cancer microenvironment may affect drug responses and thus, the available cell line data. Additionally, the whole exome sequencing pipeline of TCGA and variant calling using single nucleotide polymorphism (SNP) arrays result in differences in the coverage area. For example, the $P R Y$, which forms SC with TP53, was not found in the TCGA database. The difference in these platforms also affects the subsequent results of the analysis. Our results were analyzed by increasing the dimension of a single genetic biomarker. Thus, genes with low mutational frequencies are unlikely to produce significant results in SC. We analyzed the prognosis of the SC network in TCGA bladder and uterine cancer, focusing on the TP53 gene due to its high frequency. However, the patients' prognosis to paclitaxel is not related only to the different mutational pairs but is the result of a complex network and compensatory mechanisms. Rather than the burden of the SC pair, more research on advanced approaches using the network should be conducted. Therefore, we need to do more research on advanced approaches using the SC network in the future. There may also be tissue-specific properties that cannot be accounted for in mutation profiles. Given that this method is data intensive, it was not possible to analyze specific tissue types alone. Moreover, patients listed on TCGA were not exclusively prescribed paclitaxel; nevertheless, in uterine cancer, paclitaxel was the most used drug. Therefore, it cannot be guaranteed that the prognostic effect of the SC burden is to the responsiveness of paclitaxel alone. In TCGA database, paclitaxel was the most 
prescribed drug for uterine cancer; moreover, we confirmed the predictive power of the SC burden, which predicts the response of other chemotherapy agents.

Herein, we identified synthetic cytotoxic gene pairs that led to an increase in the cytotoxicity of the chemotherapeutic agent, paclitaxel, when the functions of two genes were disrupted simultaneously. Of these, the TP53 subnetwork of synthetic cytotoxic pairs could differentiate among prognoses of patients with uterine, bladder, and urogenital cancer found in the TCGA. However, the paclitaxel SC pairs showed significantly different responses compared to response to other cytotoxic chemotherapies. Thus, cytotoxic drug biomarkers and SC pairs may be useful to facilitate a better-informed prescription of cytotoxic chemotherapeutic agents, associated with responses that are difficult to predict.

\section{Materials and Methods}

\subsection{Cancer Cell Line Data}

We downloaded molecular profiles of 1001 cancer cell lines from the COSMIC cell line project (https:/ / cancer.sanger.ac.uk/cell_lines, version 83) [42], including the Affymetrix SNP6 array for somatic mutation profiles and copy number alterations preprocessed by the Caveman, Pindel, and PICNIC algorithms [43-45]. Only variants located in the cDNA region were used. The variants were filtered out based on the data from the NHLBI GO Exome Sequencing Project (frequency < 0.00025) and the 1000 Genomes project (frequency $<0.0014$ ) to remove sequencing artifacts and germline variants [46]. SNPs with minor allele frequency were removed.

\subsection{Gene Disruption in Cancer Cell Line Project}

Variant Effect Predictor (VEP) provided by Ensembl was used to annotate the SIFT score and consequence information for each variant $[47,48]$. Copy number estimation was derived from the PICNIC algorithm. Homozygous gene deletions were defined as dysfunctional. For drug response data, the natural $\log \mathrm{IC}_{50}$ values for all paclitaxel-treated cell lines were downloaded from the GDSC (http:/ / www.cancerrxgene.org/) [19,27]. There were 407 samples with copy number estimation, somatic mutation profiles, and $\mathrm{IC}_{50}$ values for paclitaxel. The $\log \mathrm{IC}_{50}$ values ranged from -6.68 to 2.17 , with a median of $3.117 \pm 1.91$.

\subsection{Somatic Mutation Profiles in Primary Tumors}

We downloaded the somatic mutation data from the TCGA GDC Data Portal (https:// portal.gdc.cancer.gov/) [22]. Variant calls from the MuTect2 pipeline were used in this study [24]. The information needed for further analysis of the somatic mutations was annotated using VEP. We only focused on somatic mutations in TCGA tumor-normal matched samples in urogenital, bladder urothelial, and uterine corpus endometrial carcinomas $[25,26]$. We used 406 and 471 patients with bladder and uterine cancer, respectively, for clinical variables and somatic mutation profiles. In accordance with the NCCN guidelines, patients with bladder and uterine cancer were treated with paclitaxel.

\subsection{Building Binary Disruption Gene Matrix}

The somatic mutation profile and copy number alterations were used to determine the disruption of the gene. A gene with intolerant missense mutations (SIFT < 0.05) or loss of function (nonsense, frameshift, start loss, or splice site region mutation) was classified as a disrupted gene. From the copy number alteration data, when gene deletions were homozygous, they were defined as disrupted genes. Finally, a disruption binary matrix composed of genes and samples was constructed.

\subsection{Identification of Synthetic Cytotoxic Interactions}

The workflow scheme for our analysis process is illustrated in Figure 1. For all possible combinations of gene pairs, the Wilcoxon test was used to evaluate the differences in paclitaxel $\mathrm{IC}_{50}$ values. We divided the samples into four groups according to the presence of loss of function mutations for two genes (i.e., one group with loss of function in both 
genes, two groups with loss of function in each gene independently, and a group with wild-type versions of both genes). Tests were performed on genes disrupted in more than $5 \%$ of samples. The test was performed only if there were at least $2.5 \%$ of the samples in each group. For each gene pair, the Wilcoxon test was performed three times for the group in which both genes were disrupted and in the other three groups. For the gene pair, a synthetic cytotoxic pair was defined when the group with a disruption in two genes showed significantly lower $\mathrm{IC}_{50}$ values than the other groups, based on a Wilcoxon test and $p$ value of 0.05 .

\subsection{Synthetic Cytotoxic Network for Paclitaxel}

Genes defined as SC pairs were analyzed using the igraph software package [49]. The synthetic cytotoxic network was visualized using the Gephi program [50]. For network visualization, each gene node was colored by the modularity class deduced by the Louvain method community detection algorithm [51]. Since TP53 is an important tumor suppressor gene that is highly mutated in various cancer types, we prioritized analyzing the genes that form SC with TP53.

\subsection{Functional Enrichment Test}

To confirm the function of the inferred gene pairs, we used the gene ontological biological process term and the Kyoto Encyclopedia of Genes and Genomes (KEGG) pathway [52,53]. GATHER is an online tool for functional enrichment analysis that interprets through enriched functions in input genes (https:/ / changlab.uth.tmc.edu/gather/gather. py) [54]. This tool integrates gene function, ontology, and pathways to provide an interpretation of genomic data analysis results with network inference. Enrichment analysis was performed with the latest version of GO and KEGG pathway using R package; Bioconductor's RDAVIDWebService version 3.12 was used for genes included in the SC network with GATHER network inference genes [55].

\subsection{Prognostic Effect of SC in TCGA Datasets}

To validate SC effects for gene pairs computationally inferred from the cell line database derived from GDSC, we confirmed the prognostic effect in the real patient database from TCGA for the SC pairs that improved the response to paclitaxel. It was difficult to test the significance of genes with low mutation frequencies. Therefore, we only performed survival analysis for TP53 synthetic cytotoxic subnetwork gene pairs. Patients were divided into two groups, with and without TP53 mutations. For each group, patients were subdivided according to the burden of the mutation forming SC with TP53. Finally, Cox regression with Firth's penalized likelihood method was used based on the burden of the mutation, and the hazard ratio of the burden was compared between the TP53 mutant and nonmutant groups to confirm the prognostic effect of the SC pair [56].

Supplementary Materials: The following are available online at https:/ /www.mdpi.com/1422-006 7/22/3/1097/s1, Table S1: Lists the count of SC pairs made up by patients. In each group, patients were clustered based on the number of SC pairs, and the order of fewer SC pairs was first. Table S2: A multivariate Cox proportional hazard analysis of SC burden with pathologic stage.

Author Contributions: J.H.L. led the integrative analyses and wrote the initial draft. K.H.L. revised the draft and managed the project. J.H.K. designed and organized the experiments. All authors have read and agreed to the published version of the manuscript.

Funding: This research was supported by the Basic Science Research Program through the National Research Foundation of Korea (NRF) funded by the Ministry of Education (NRF-2018R1D1A1A02086109).

Institutional Review Board Statement: Not applicable.

Informed Consent Statement: Not applicable. 
Data Availability Statement: The data analyzed in this study is available from public repositories. These data can be found here: TCGA, https://portal.gdc.cancer.gov/; GDSC, http://www. cancerrxgene.org/.

Acknowledgments: We appreciated the patients and their families who generously donated their tissues to TCGA/GDSC, as well as the members who collected and disclosed the valuable data.

Conflicts of Interest: The authors declare no conflict of interest.

$\begin{array}{ll}\text { Abbreviations } \\ \text { EC50 } & \text { Half-maximal effective concentration } \\ \text { FDR } & \text { False discovery rate } \\ \text { GATHER } & \text { Gene annotation tool to help explain relationships } \\ \text { GDSC } & \text { Genomics of drug sensitivity in cancer } \\ \text { GO } & \text { Gene ontology } \\ \text { IC50 } & \text { Half-maximal inhibitory concentration } \\ \text { SC } & \text { Synthetic cytotoxicity } \\ \text { SNP } & \text { Single nucleotide polymorphism } \\ \text { TCGA } & \text { The cancer genome atlas } \\ \text { VEP } & \text { Variant effect predictor }\end{array}$

\section{References}

1. Twelves, C.; Jove, M.; Gombos, A.; Awada, A. Cytotoxic chemotherapy: Still the mainstay of clinical practice for all subtypes metastatic breast cancer. Crit. Rev. Oncol. Hematol. 2016, 100, 74-87. [CrossRef]

2. $\quad$ Ribeiro, J.T.; Macedo, L.T.; Curigliano, G.; Fumagalli, L.; Locatelli, M.; Dalton, M.; Quintela, A.; Carvalheira, J.B.C.; Manunta, S.; Mazzarella, L.; et al. Cytotoxic drugs for patients with breast cancer in the era of targeted treatment: Back to the future? Ann. Oncol. 2012, 23, 547-555. [CrossRef]

3. Dembic, Z. Antitumor Drugs and Their Targets. Molecules 2020, 25, 5776. [CrossRef]

4. Falzone, L.; Salomone, S.; Libra, M. Evolution of cancer pharmacological treatments at the turn of the third millennium. Front. Pharmacol. 2018, 9, 1300. [CrossRef] [PubMed]

5. Ma, P.; Mumper, R.J. Paclitaxel nano-delivery systems: A comprehensive review. J. Nanomed. Nanotechnol. 2013, 4, 1000164. [CrossRef] [PubMed]

6. Xu, C.-Z.; Shi, R.-J.; Chen, D.; Sun, Y.-Y.; Wu, Q.-W.; Wang, T.; Wang, P.-H. Potential biomarkers for paclitaxel sensitivity in hypopharynx cancer cell. Int. J. Clin. Exp. Pathol. 2013, 6, 2745. [PubMed]

7. Perez-Ortiz, A.C.; Villarreal-Garza, C.; Villa-Romero, A.; Lopez, J.C.C.; Ramirez-Sanchez, I.; Luna-Angulo, A.; Guerrero-Solorzano, J.C.; Matus, J.A.; Diaz-Chavez, J.; Garcia-Alvarez, B.A.; et al. Pharmacogenetic biomarkers associated with paclitaxel response in Mexican women with locally advanced breast cancer. 2017. [CrossRef]

8. Paradiso, A.; Mangia, A.; Chiriatti, A.; Tommasi, S.; Zito, A.; Latorre, A.; Schittulli, F.; Lorusso, V. Biomarkers predictive for clinical efficacy of taxol-based chemotherapy in advanced breast cancer. Ann. Oncol. 2005, 16, iv14-iv19. [CrossRef] [PubMed]

9. Chang, Y.; Park, H.; Yang, H.-J.; Lee, S.; Lee, K.-Y.; Kim, T.S.; Jung, J.; Shin, J.-M. Cancer drug response profile scan (CDRscan): A deep learning model that predicts drug effectiveness from cancer genomic signature. Sci. Rep. 2018, 8, 8857. [CrossRef]

10. O'Neil, N.J.; Bailey, M.L.; Hieter, P. Synthetic lethality and cancer. Nat. Rev. Genet. 2017, 18, 613-623. [CrossRef]

11. Kaelin, W.G. The concept of synthetic lethality in the context of anticancer therapy. Nat. Rev. Cancer 2005, 5, 689-698. [CrossRef] [PubMed]

12. Lee, J.S.; Das, A.; Jerby-Arnon, L.; Arafeh, R.; Auslander, N.; Davidson, M.; McGarry, L.; James, D.; Amzallag, A.; Park, S.G.; et al. Harnessing synthetic lethality to predict the response to cancer treatment. Nat. Commun. 2018, 9, 2546. [CrossRef] [PubMed]

13. Apaolaza, I.; San José-Eneriz, E.; Tobalina, L.; Miranda, E.; Garate, L.; Agirre, X.; Prósper, F.; Planes, F.J. An in-silico approach to predict and exploit synthetic lethality in cancer metabolism. Nat. Commun. 2017, 8, 459. [CrossRef] [PubMed]

14. Li, X.; O'Neil, N.J.; Moshgabadi, N.; Hieter, P. Synthetic cytotoxicity: Digenic interactions with TEL1/ATM mutations reveal sensitivity to low doses of camptothecin. Genetics 2014, 197, 611-623. [CrossRef] [PubMed]

15. Jerby-Arnon, L.; Pfetzer, N.; Waldman, Y.Y.; McGarry, L.; James, D.; Shanks, E.; Seashore-Ludlow, B.; Weinstock, A.; Geiger, T.; Clemons, P.A.; et al. Predicting cancer-specific vulnerability via data-driven detection of synthetic lethality. Cell 2014, 158, 1199-1209. [CrossRef] [PubMed]

16. Liu, L.; Chen, X.; Hu, C.; Zhang, D.; Shao, Z.; Jin, Q.; Yang, J.; Xie, H.; Liu, B.; Hu, M.; et al. Synthetic lethality-based identification of targets for anticancer drugs in the human signaling network. Sci. Rep. 2018, 8, 8440. [CrossRef]

17. Jang, K.; Park, M.J.; Park, J.S.; Hwangbo, H.; Sung, M.K.; Kim, S.; Jung, J.; Lee, J.W.; Ahn, S.-H.; Chang, S.; et al. Computational inference of cancer-specific vulnerabilities in clinical samples. Genome Biol. 2020, 21, 155. [CrossRef] [PubMed]

18. Guo, J.; Liu, H.; Zheng, J. SynLethDB: Synthetic lethality database toward discovery of selective and sensitive anticancer drug targets. Nucl. Acids Res. 2016, 44, D1011-D1017. [CrossRef] 
19. Yang, W.; Soares, J.; Greninger, P.; Edelman, E.J.; Lightfoot, H.; Forbes, S.; Bindal, N.; Beare, D.; Smith, J.A.; Thompson, I.R.; et al. Genomics of drug sensitivity in cancer (GDSC): A resource for therapeutic biomarker discovery in cancer cells. Nucl. Acids Res. 2012, 41, D955-D961. [CrossRef]

20. Zhang, X.; Xu, R.; Zhu, B.; Yang, X.; Ding, X.; Duan, S.; Xu, T.; Zhuang, Y.; Han, M. Syne-1 and Syne-2 play crucial roles in myonuclear anchorage and motor neuron innervation. Development 2007, 134, 901-908. [CrossRef]

21. Ahn, E.-Y.; DeKelver, R.C.; Lo, M.-C.; Nguyen, T.A.; Matsuura, S.; Boyapati, A.; Pandit, S.; Fu, X.-D.; Zhang, D.-E. SON controls cell-cycle progression by coordinated regulation of RNA splicing. Mol. Cell 2011, 42, 185-198. [CrossRef] [PubMed]

22. Weinstein, J.N.; Collisson, E.A.; Mills, G.B.; Shaw, K.R.M.; Ozenberger, B.A.; Ellrott, K.; Shmulevich, I.; Sander, C.; Stuart, J.M.; Network, C.G.A.R.; et al. The cancer genome atlas pan-cancer analysis project. Nat. Genet. 2013, 45, 1113. [CrossRef] [PubMed]

23. Akbari, B.; Farajnia, S.; Ahdi Khosroshahi, S.; Safari, F.; Yousefi, M.; Dariushnejad, H.; Rahbarnia, L. Immunotoxins in cancer therapy: Review and update. Int. Rev. Immunol. 2017, 36, 207-219. [CrossRef] [PubMed]

24. Cibulskis, K.; Lawrence, M.S.; Carter, S.L.; Sivachenko, A.; Jaffe, D.; Sougnez, C.; Gabriel, S.; Meyerson, M.; Lander, E.S.; Getz, G. Sensitive detection of somatic point mutations in impure and heterogeneous cancer samples. Nat. Biotechnol. 2013, 31, 213-219. [CrossRef] [PubMed]

25. Lu, Z.; Yeh, T.-K.; Tsai, M.; Au, J.L.-S.; Wientjes, M.G. Paclitaxel-loaded gelatin nanoparticles for intravesical bladder cancer therapy. Clin. Cancer Res. 2004, 10, 7677-7684. [CrossRef]

26. Park, D.C.; Kim, J.H.; Lew, Y.O.; Kim, D.H.; Namkoong, S.E. Phase II trial of neoadjuvant paclitaxel and cisplatin in uterine cervical cancer. Gynecol. Oncol. 2004, 92, 59-63. [CrossRef]

27. Iorio, F.; Knijnenburg, T.A.; Vis, D.J.; Bignell, G.R.; Menden, M.P.; Schubert, M.; Aben, N.; Gonçalves, E.; Barthorpe, S.; Lightfoot, H.; et al. A landscape of pharmacogenomic interactions in cancer. Cell 2016, 166, 740-754. [CrossRef]

28. Al-Lazikani, B.; Banerji, U.; Workman, P. Combinatorial drug therapy for cancer in the post-genomic era. Nat. Biotechnol. 2012, 30, 679-692. [CrossRef]

29. Lee, J.H.; Park, Y.R.; Jung, M.; Lim, S.G. Gene regulatory network analysis with drug sensitivity reveals synergistic effects of combinatory chemotherapy in gastric cancer. Sci. Rep. 2020, 10, 3932. [CrossRef]

30. Manica, M.; Oskooei, A.; Born, J.; Subramanian, V.; Sáez-Rodriguez, J.; Rodríguez Martínez, M. Toward explainable anticancer compound sensitivity prediction via multimodal attention-based convolutional encoders. Mol. Pharm. 2019, 16, 4797-4806. [CrossRef]

31. Ali, M.; Aittokallio, T. Machine learning and feature selection for drug response prediction in precision oncology applications. Biophys. Rev. 2019, 11, 31-39. [CrossRef] [PubMed]

32. Turki, T.; Wei, Z. A link prediction approach to cancer drug sensitivity prediction. BMC Syst. Biol. 2017, 11, 94. [CrossRef] [PubMed]

33. Oskooei, A.; Manica, M.; Mathis, R.; Martinez, M.R. Network-based biased tree ensembles (NetBiTE) for drug sensitivity prediction and drug sensitivity biomarker identification in cancer. Sci. Rep. 2019, 9, 15918. [CrossRef] [PubMed]

34. Mansilla, S.; Bataller, M.; Portugal, J. Mitotic catastrophe as a consequence of chemotherapy. Anti-Cancer Agents Med. Chem. 2006, 6, 589-602. [CrossRef]

35. Page, R.; Takimoto, C. Principles of chemotherapy. In Cancer Management: A Multidisciplinary Approach Medical, Surgical Radiation Oncology; Pazdur, R., Coia, L.R., Hoskins, W.J., Wagman, L.D., Eds.; PRR: New York, NY, USA, 2004; pp. 21-38.

36. Nikanjam, M.; Riviere, P.; Goodman, A.; Barkauskas, D.A.; Frampton, G.; Kurzrock, R. Tumor mutational burden is not predictive of cytotoxic chemotherapy response. Oncoimmunology 2020, 9, 1781997. [CrossRef]

37. Mei, P.; Freitag, C.E.; Wei, L.; Zhang, Y.; Parwani, A.V.; Li, Z. High tumor mutation burden is associated with DNA damage repair gene mutation in breast carcinomas. Diagn Pathol. 2020, 15, 1-7. [CrossRef]

38. Burrell, R.A.; Swanton, C. Tumour heterogeneity and the evolution of polyclonal drug resistance. Mol. Oncol. 2014, 8, 1095-1111. [CrossRef]

39. Wang, R.; Han, Y.; Zhao, Z.; Yang, F.; Chen, T.; Zhou, W.; Wang, X.; Qi, L.; Zhao, W.; Guo, Z.; et al. Link synthetic lethality to drug sensitivity of cancer cells. Brief. Bioinform. 2019, 20, 1295-1307. [CrossRef]

40. Sachs, M.D.; Lenk, S.V. TP53 gene mutations as an independent marker for urinary bladder cancer progression. Int. J. Mol. Med. 2008, 21, 655-661.

41. Pennington, K.P.; Walsh, T.; Lee, M.; Pennil, C.; Novetsky, A.P.; Agnew, K.J.; Thornton, A.; Garcia, R.; Mutch, D.; King, M.-C.; et al. BRCA1, TP53, and CHEK2 germline mutations in uterine serous carcinoma. Cancer 2013, 119, 332-338. [CrossRef]

42. Forbes, S.A.; Beare, D.; Boutselakis, H.; Bamford, S.; Bindal, N.; Tate, J.; Cole, C.G.; Ward, S.; Dawson, E.; Ponting, L.; et al. COSMIC: Somatic cancer genetics at high-resolution. Nucleic Acids Res. 2017, 45, D777-D783. [CrossRef] [PubMed]

43. Jones, D.; Raine, K.M.; Davies, H.; Tarpey, P.S.; Butler, A.P.; Teague, J.W.; Nik-Zainal, S.; Campbell, P.J. cgpCaVEManWrapper: Simple execution of CaVEMan in order to detect somatic single nucleotide variants in NGS data. Curr. Protoc. Bioinform. 2016, 56, 10-15. [CrossRef] [PubMed]

44. Ye, K.; Schulz, M.H.; Long, Q.; Apweiler, R.; Ning, Z. Pindel: A pattern growth approach to detect break points of large deletions and medium sized insertions from paired-end short reads. Bioinformatics 2009, 25, 2865-2871. [CrossRef] [PubMed]

45. Greenman, C.D.; Bignell, G.; Butler, A.; Edkins, S.; Hinton, J.; Beare, D.; Swamy, S.; Santarius, T.; Chen, L.; Widaa, S.; et al. PICNIC: An algorithm to predict absolute allelic copy number variation with microarray cancer data. Biostatistics 2010, 11, 164-175. [CrossRef] [PubMed] 
46. Siva, N. 1000 Genomes project. Nat. Biotechnol. 2008, 26, 256. [CrossRef] [PubMed]

47. McLaren, W.; Gil, L.; Hunt, S.E.; Riat, H.S.; Ritchie, G.R.S.; Thormann, A.; Flicek, P.; Cunningham, F. The ensembl variant effect predictor. Genome Biol. 2016, 17, 122. [CrossRef]

48. Vaser, R.; Adusumalli, S.; Leng, S.N.; Sikic, M.; Ng, P.C. SIFT missense predictions for genomes. Nat. Protoc. 2016, 11, 1. [CrossRef]

49. Csardi, G.; Nepusz, T. The igraph software package for complex network research. Int. J. Complex. Syst. 2006, 1695, 1-9.

50. Bastian, M.; Heymann, S.; Jacomy, M. Gephi: An open source software for exploring and manipulating networks. In Proceedings of the Third International AAAI Conference on Weblogs and Social Media, California, CA, USA, 17-20 May 2009.

51. Blondel, V.D.; Guillaume, J.-L.; Lambiotte, R.; Lefebvre, E. Fast unfolding of communities in large networks. J. Stat. Mech. Theory Exp. 2008, 2008, P10008. [CrossRef]

52. Ashburner, M.; Ball, C.A.; Blake, J.A.; Botstein, D.; Butler, H.; Cherry, J.M.; Davis, A.P.; Dolinski, K.; Dwight, S.S.; Eppig, J.T.; et al. Gene ontology: Tool for the unification of biology. Nat. Genet. 2000, 25, 25-29. [CrossRef]

53. Kanehisa, M.; Goto, S. KEGG: Kyoto encyclopedia of genes and genomes. Nucleic Acids Res. 2000, 28, 27-30. [CrossRef] [PubMed]

54. Chang, J.T.; Nevins, J.R. GATHER: A systems approach to interpreting genomic signatures. Bioinformatics 2006, 22, 2926-2933. [CrossRef] [PubMed]

55. Fresno, C.; Fernández, E.A. RDAVIDWebService: A versatile R interface to DAVID. Bioinformatics 2013, 29, 2810-2811. [CrossRef] [PubMed]

56. Ploner, M.; Heinze, G. coxphf: Cox regression with Firth's penalized likelihood. R Found. Stat. Comput. 2015. Available online: https: / CRAN.R-project.org/package=coxphf (accessed on 22 January 2021). 